\title{
Dual Enzyme Electrode with Optical Specificity for L- and D-Amino Acids
}

\author{
Toshio YAO ${ }^{\dagger}$ Kazuyoshi TAKaShIMA, and Youko NANJYo \\ Department of Applied Chemistry, Graduate School of Engineering, Osaka Prefecture University, \\ 1-1 Gakuencho, Sakai, Osaka 599-8531, Japan
}

(Received June 17, 2002; Accepted July 17, 2002)

\begin{abstract}
Amino acid oxidases are selective for amino acids, but not for particular amino acids. That is, they act on a considerable number of amino acids. In addition, amino acid oxidases have an optical specificity for D- or L-isomers; L-amino acid oxidase (L-AAO) is specific for L-amino acids and D-amino acid oxidase (D-AAO) is specific for D-amino acids. The general enzyme reaction is
\end{abstract}

$$
\text { Amino acids }+\mathrm{O}_{2}+\mathrm{H}_{2} \mathrm{O} \stackrel{\text { AAO }}{\longrightarrow} \text { 2-oxo acids }+\mathrm{NH}_{3}+\mathrm{H}_{2} \mathrm{O}_{2} \text {. }
$$

Many research groups have proposed the enzyme sensors for the specific detection of $\mathrm{L}^{-1-7}$ or $\mathrm{D}^{-3,8,9}$ isomers of amino acids. Most of the enzyme sensors proposed are based on the amperometric ${ }^{1,2,4-6,8}$ and potentiometric ${ }^{7}$ detections or chemiluminometric $^{3,9}$ detection of hydrogen peroxide or ammonia produced by the amino acid oxidases. In addition, the development of new biosensors which may enable the simultaneous determination of L- and D-isomers of amino acids is also important, but it had not been achieved except for the successive detection ${ }^{3,10}$ of both isomers.

In this note, a dual enzyme electrode suitable for the simultaneous amperometric detection of $\mathrm{D}$ - and $\mathrm{L}$-amino acids is described. The proposed dual electrode consists of two platinum disks modified by an L-AAO or D-AAO membrane cross-linked by glutaraldehyde. Furthermore, the electropolymerization to coat with a thin film of poly(1,2diaminobenzene) was subsequently carried out to protect the electrode from direct (nonenzymatic) oxidation of electroactive amino acids such as methionine and tyrosine or electroactive interferents such as L-ascorbate, urate, and cysteine, which may otherwise cause electrode fouling. The analytical performance of the dual enzyme electrode is assessed under flow-injection conditions, particularly on substrate selectivity within a group of amino acids and on optical specificity for D- and L-isomers of amino acids.

\section{Experimental}

\section{Reagents}

D-AAO (EC 1.4.3.3, $9.9 \mathrm{U} \mathrm{mg}^{-1}$ of solid from porcine kidney), L-AAO (EC 1.4.3.2, $4 \mathrm{U} \mathrm{mg}^{-1}$ of solid from Crotalus adamanteus), and the D- and L-forms of alanine, arginine, histidine, leucine, lysine, methionine, phenylalanine, proline, serine, tyrosine, and valine were obtained from Sigma. Bovine serum albumin (BSA, 96 - $99 \%$ albumin), glutaraldehyde (20\%

† To whom correspondence should be addressed. solution), ascorbic acid, uric acid, L-cysteine, and 1,2diaminobenzene were obtained from Wako. They were used as received. The phosphate buffers were prepared from sodium dihydrogen phosphate. Distilled water purified with the use of a Millipore Milli-Q system was used throughout.

\section{Construction of the dual enzyme electrode}

A BAS cross-flow electrochemical flow-cell was used for the surface modification of the electrode. The electrode assembly consisted of a dual electrode with two platinum disks $(3 \mathrm{~mm}$ in diameter) as a working electrode, a silver-silver chloride reference electrode, and a stainless-steel as an auxiliary electrode. Prior to the enzyme coating, the surface of the platinum disks was polished with $6 \mu \mathrm{m}$ diamond particles (BAS) and then with $0.05 \mu \mathrm{m}$ alumina particles (BAS), then rinsed with distilled water and allowed to air-dry. Both the platinum disks were then modified by cross-linking D-AAO or L-AAO and BSA using glutaraldehyde. The method is similar to that described previously ${ }^{11}$ and is as follows. The D-AAO $(0.8 \mathrm{mg} ; 7.9 \mathrm{U})$ or L-AAO $(0.8 \mathrm{mg} ; 3.2 \mathrm{U})$ and $7.5 \mu \mathrm{l}$ of $10 \%$ $(\mathrm{w} / \mathrm{v})$ aqueous BSA were added to $18 \mu \mathrm{l}$ of $0.02 \mathrm{M}$ sodium phosphate buffer ( $\mathrm{pH} 7.0)$. A $3 \mu$ portion of a $4 \%(\mathrm{v} / \mathrm{v})$ solution of glutaraldehyde was added to each solution and the combinations mixed well. A $3 \mu \mathrm{l}$ aliquot of the resulting solutions was carefully spread out onto each of two platinum disks. The membranes were allowed to form for half a day at room temperature, open to the air. In this way, each of two platinum disks of the dual electrode was modified with the LAAO or D-AAO membrane cross-linked with BSA by glutaraldehyde. Then the dual electrode was assembled into the electrochemical flow-cell and washed with $0.1 \mathrm{M}$ glycine buffer $(\mathrm{pH} 7.5)$ to remove the excess of enzymes and the residual aldehyde groups onto the enzyme membranes. Furthermore, the electropolymerization to coat with a thin film of poly(1,2diaminobenzene) was subsequently carried out by holding the dual enzyme electrode at $1.0 \mathrm{~V} v s$. $\mathrm{Ag} / \mathrm{AgCl}$ with a Fuso HECS 966 multichannel potentiostat for $45 \mathrm{~min}$, in a flowing stream (pumped at a flow rate of $0.3 \mathrm{ml} \mathrm{min}{ }^{-1}$ ) of a solution of 1,2diaminobenzene $(10 \mathrm{mM})$ in $0.1 \mathrm{M}, \mathrm{pH} 7.0$, sodium phosphate buffer, by a procedure similar to that described by Sasso et al. ${ }^{12}$ After the electropolymerization, the dual enzyme electrode was washed exhaustively with the same phosphate buffer. The completed electrode was stored in phosphate buffer $(0.1 \mathrm{M}, \mathrm{pH}$ 7.0) at $4-5^{\circ} \mathrm{C}$ when not in use.

\section{Apparatus and procedures}

The apparatus for the FIA measurements was similar to that described previously. ${ }^{13}$ The FIA system consisted of an Eicom 

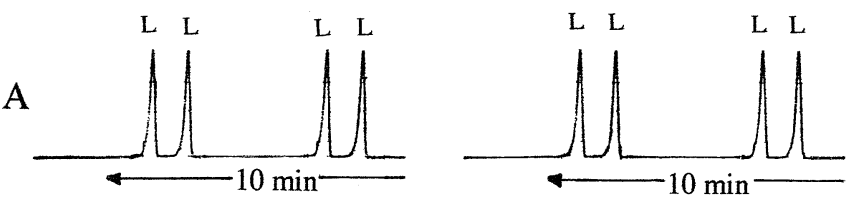

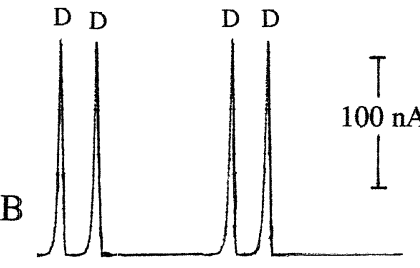

in parallel

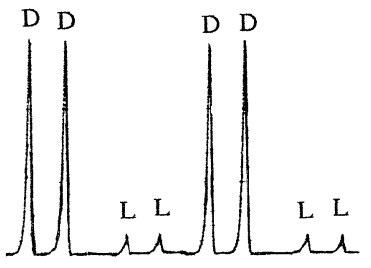

in series
Fig. 1 Flow injection signals obtained by alternate injections of 0.1 $\mathrm{mM}$ L-phenylalanine (L) and $0.1 \mathrm{mM}$ D-phenylalanine (D) at the dual enzyme electrodes arranged in parallel and in series, respectively: (A) FIA signals at L-amino acid sensing part; (B) FIA signals at D-amino acid sensing part. In the in series arrangement, L-amino acid and Damino acid sensing parts are arranged as the upstream and downstream electrodes, respectively, for the carrier flow direction. Carrier solution, $0.1 \mathrm{M}$ sodium phosphate buffer ( $\mathrm{pH}$ 8.0) pumped at a flow rate of $0.2 \mathrm{ml} \mathrm{min}^{-1}$. Applied potential; $+0.6 \mathrm{~V} v s$. Ag/AgCl.

double-plunger micropump, an injector (Rheodyne 7125) with a sample loop of $100 \mu$, a dual enzyme electrode, a Fuso HECS 966 multichannel potentiostat, and a multipen recorder (Nippon Denshi Kagaku U-638). The dual electrode was connected to the outlet of the injector with an $100 \mathrm{~cm}$ length of PTFE coil ( $0.5 \mathrm{~mm}$ i.d.). The $0.1 \mathrm{M}$ sodium phosphate buffer ( $\mathrm{pH}$ 8.0) was pumped as a working carrier solution, at a constant flow rate. Sample solutions $(20 \mu \mathrm{l})$ were injected with a microsyringe.

\section{Results and Discussion}

Two sensing parts of the dual enzyme electrode can be arranged in series or in parallel for the carrier flow direction. Figure 1 shows flow injection current-time profiles for the alternate injections of L- and D-phenylalanines, which are observed at the dual enzyme electrodes arranged in parallel and in series, respectively. In the dual enzyme electrode arranged in parallel, the L-amino acid and D-amino acid sensing parts responded selectively to L- and D-phenylalanines, respectively, and there was no apparent cross reactivity between the two sensing parts. However, when L-amino acid and D-amino acid sensing parts were arranged in series as upstream and downstream electrodes, respectively, for the carrier flow direction, the D-amino acid sensing part gave a small response for the L-phenylalanine injection. This means that the upstream electrode acts as an enzyme microreactor; thus some fractions of the hydrogen peroxide generated enzymatically at the upstream electrode are detected at the downstream electrode. From this result, the in-parallel arrangement was found to be more suitable for the simultaneous detection of $\mathrm{L}-$ and $\mathrm{D}$-amino acids.

At an applied potential of $0.6 \mathrm{~V}$ versus $\mathrm{Ag} / \mathrm{AgCl}$, however, two sensing parts coated with enzyme membrane alone gave fairly large responses to the electroactive interferentes such as ascorbate, urate, and cysteine, as shown in Table 1. In addition, methionine and tyrosine were directly oxidized at the electrode surface (see Table 1). Furthermore, some of these electroactive compounds caused a decrease in the sensitivity due to electrode fouling. In contrast, the hybridization of poly(1,2-
Table 1 Effect of poly(1,2-diaminobenzene) film hybridized to enzyme-sensing parts of dual enzyme electrode

\begin{tabular}{lcccc}
\hline \multirow{2}{*}{$\begin{array}{c}\text { Substrate } \\
(0.5 \mathrm{mM} \text { each })\end{array}$} & \multicolumn{2}{c}{$\begin{array}{c}\text { D-Amino acid } \\
\text { sensing part } / \mathrm{nA}\end{array}$} & \multicolumn{2}{c}{$\begin{array}{c}\text { L-Amino acid } \\
\text { sensing parta/nA }\end{array}$} \\
\cline { 2 - 5 } & without film & with film & without film & with film \\
\hline Ascorbic acid & 810 & 4 & 830 & 4 \\
Uric acid & 750 & 5 & 770 & 6 \\
Cysteine & 620 & 2 & 640 & 3 \\
D-Methionine & 1260 & 600 & 140 & 2 \\
L-Methionine & 172 & 2 & 510 & 170 \\
D-Tyrosine & 1450 & 632 & 285 & 2 \\
L-Tyrosine & 206 & 3 & 585 & 232 \\
\hline
\end{tabular}

a. Comparison of response (peak current) obtained by dual enzyme electrode without and with poly(1,2-diaminobenzene) film.

diaminobenzene) film to enzyme membrane was effective to block the access of such electroactive compounds to the electrode surface, by the size-exclusion function of poly $(1,2-$ diaminobenzene) film as described before. ${ }^{14,15}$ As shown in Table 1, two sensing parts with poly(1,2-diaminobenzene) film gave optically specific FIA signals to D- and L-isomers of methionine and tyrosine without direct oxidation at the electrode surface. Furthermore, this dual enzyme electrode effectively excluded ascorbate, urate, and cysteine below $1 \mathrm{mM}$.

Experiments were first carried out to establish the optimum conditions for the simultaneous detection of L- and D-isomers of amino acids using the dual enzyme electrode with poly(1,2diaminobenzene) film, especially for the $\mathrm{pH}$ and the flow rate of the carrier solution. Sodium phosphate buffers $(0.1 \mathrm{M})$ at various $\mathrm{pH}$ values were tested as the carrier solution; both sensing parts of the dual enzyme electrode gave maximum responses over the wide $\mathrm{pH}$ range of $7.5-9.0$ for the L- and Disomers $(0.1 \mathrm{mM}$ each $)$ of phenylalanine and leucine, respectively. Therefore, $0.1 \mathrm{M}$ sodium phosphate buffer at $\mathrm{pH}$ 8.0 was selected as the carrier buffer. The carrier flow rate is related to the residence time of the sample zone in the dual enzyme electrode. FIA signals for a solution containing 0.1 $\mathrm{mM}$ each of the $\mathrm{L}$ - and D-phenylalanines were recorded at the carrier flow rates in the range of $0.1-0.5 \mathrm{ml} \mathrm{min}{ }^{-1}$. The signal intensity increased with decreasing flow rate. The time required for the simultaneous determination, however, became excessive at low flow rates, and so a flow rate of $0.2 \mathrm{ml} \mathrm{min}^{-1}$ was selected. This provided relatively good sensitivity and reasonable sample throughput (about 120 samples $^{-1}$ ).

Under such experimemtal conditions, current responses for Dor L-isomers of a variety of amino acids were recorded simultaneously by the dual enzyme electrode. As shown in Table 2, the D-amino acid sensing part was not selective among amino acids and responded to a variety of D-amino acids, but not to L-amino acids. In contrast, the L-amino acid sensing part responded sensitively to L-isomers of four particular amino acids (leucine, methionine, phenylalanine, and tyrosine), but gave small or no signal for other amino acids. Thus the Damino acid and L-amino acid sensing parts of the dual enzyme electrode were optically specific for D- and L-isomers of amino acids, respectively, but showed different sensitivities for the various amino acids.

The D-amino acid and L-amino acid sensing parts responded linearly to the concentration for almost all the amino acids and for four amino acids of leucine, methionine, phenylalanine, and tyrosine, respectively, over the dynamic range of $1 \times 10^{-6}-1.2 \times$ $10^{-3} \mathrm{M}$. The lowest concentrations which could be detected by 
Table 2 Substrate selectivity and optical specificity of the dual enzyme electrode for D- and L-isomers of amino acids

\begin{tabular}{lcc}
\hline \multirow{2}{*}{$\begin{array}{c}\text { Amino acid } \\
\text { (0.5 mM each) }\end{array}$} & \multicolumn{2}{c}{ Current/nA } \\
\cline { 2 - 3 } & $\begin{array}{c}\text { D-Amino acid } \\
\text { sensing part }\end{array}$ & $\begin{array}{c}\text { L-Amino acid } \\
\text { sensing part }\end{array}$ \\
\hline D-Alanine & 580 & n.d. \\
L-Alanine & n.d. & 2 \\
D-Arginine & 188 & n.d. \\
L-Arginine & n.d. & 26 \\
D-Histidine & 132 & n.d. \\
L-Histidine & n.d. & 25 \\
D-Leucine & 488 & 2 \\
L-Leucine & n.d. & 132 \\
D-Lysine & 40 & n.d. \\
L-Lysine & n.d. & 2 \\
D-Methionine & 600 & n.d. \\
L-Methionine & n.d. & 170 \\
D-Phenylalanine & 400 & n.d. \\
L-Phenylalanine & n.d. & 186 \\
D-Proline & 890 & n.d. \\
L-Proline & n.d. & n.d. \\
D-Serine & 333 & n.d. \\
L-Serine & n.d. & n.d. \\
D-Tyrosine & 632 & n.d. \\
L-Tyrosine & n.d. & 232 \\
D-Valine & 690 & n.d. \\
L-Valine & n.d. & n.d. \\
\hline
\end{tabular}

n.d.: not detected.

the proposed dual enzyme electrode were $(0.5-1) \times 10^{-6} \mathrm{M}$ for the above amino acids (signal to noise ratio $=3$ ). The reproducibility of the measurements was $0.8-1.5 \%(n=7)$ at a concentration level of $1 \times 10^{-4} \mathrm{M}$.

When the dual enzyme electrode were stored at $4^{\circ} \mathrm{C}$ in optimum buffer, it retained most of its activity for six weeks. However, the operational stability was not good when the measurement was carried out for $3 \mathrm{~h}$ per day. After three weeks, the activities of both sensing parts of the dual enzyme electrode decreased to $52-65 \%$ of their original values.
In conclusion, the proposed dual enzyme electrode was found to be useful as an optically specific detector for D- and Lisomers of amino acids. However, such an analytical usefulness was restricted to the simultaneous detection of D- and L-isomers of four particular amino acids (leucine, methionine, phenylalanine, and tyrosine), because the L-amino acid sensing part of the dual enzyme electrode responded only to the above particular amino acids. In contrast, the D-amino acid sensing part responded sensitively to D-isomers of almost all the amino acids and, therefore, is considered available as an optically specific D-amino acid detector for high performance liquid chromatography.

\section{References}

1. G. L. Radu and P. R. Coulet, Analusis, 1993, 21, 101.

2. J. C. Cooper and F. Schubert, Electroanalysis, 1994, 6, 957.

3. J. Z. Li, Z. J. Zhang, and L. Li, Talanta, 1994, 41, 1999.

4. M. Situmorang, J. J. Gooding, and D. B. Hibbert, Anal. Chim. Acta, 1999, 394, 211.

5. J. H. Pei and X. Y. Li, Fresenius J. Anal. Chem., 2000, $367,707$.

6. J. S. Kim, J. D. Pike, D. Coucouvanis, and M. E. Meyerhoff, Electroanalysis, 2000, 12, 1258

7. Y. C. Lee and M. H. Huh, J. Food Biochem., 1999, 23, 173.

8. G. Arai, T. Noma, M. Hayashi, and I. Yasumori, J. Electroanal. Chem., 1998, 452, 43.

9. Z. J. Zhang, Z. L. Gong, and W. B. Ma, Microchem. J., 1995, 52, 131.

10. T. Yao and T. Wasa, Anal. Chim. Acta, 1988, 209, 259.

11. T. Yao, Anal. Chim. Acta, 1983, 148, 27.

12. S. V. Sasso, R. J. Pierce, R. Walla, and A. M. Yacynych, Anal. Chem., 1990, 62, 1111.

13. T. Yao and A. Uno, Bunseki Kagaku, 2000, 49, 369.

14. T. Yao, M. Satomura, and T. Nakahara, Anal. Chim. Acta, 1994, 296, 271.

15. T. Yao, M. Satomura, and T. Nakahara, Talanta, 1994, 41, 2113. 